This article was downloaded by:[ENEA]

On: 16 July 2007

[ENEA]

Access Details: [subscription number 772812123]

Publisher: Taylor \& Francis

Informa Ltd Registered in England and Wales Registered Number: 1072954

Registered office: Mortimer House, 37-41 Mortimer Street, London W1T 3JH, UK

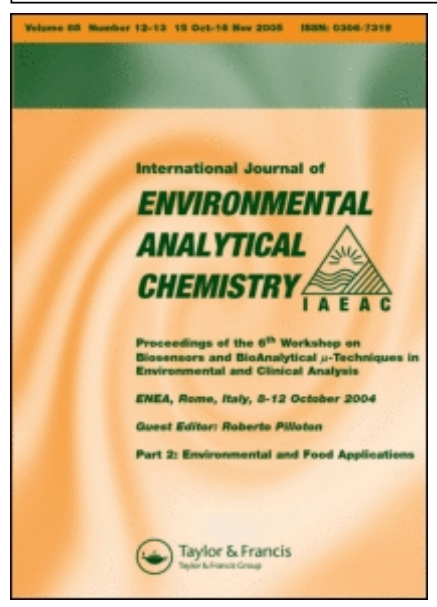

International Journal of Environmental Analytical Chemistry

Publication details, including instructions for authors and subscription information: http://www.informaworld.com/smpp/title content=t713640455

\title{
Biosensors based on gold nanoelectrode ensembles and screen printed electrodes
}

Online Publication Date: 01 August 2007

To cite this Article: Vastarella, Walter, Della Seta, Livia, Masci, Amedeo, Maly, Jan, De Leo, Manuela, Moretto, Ligia Maria and Pilloton, Roberto , (2007)

'Biosensors based on gold nanoelectrode ensembles and screen printed electrodes', International Journal of Environmental Analytical Chemistry, 87:10, 701 - 714

To link to this article: DOI: $10.1080 / 03067310701332626$

URL: http://dx.doi.org/10.1080/03067310701332626

\section{PLEASE SCROLL DOWN FOR ARTICLE}

Full terms and conditions of use: http://www.informaworld.com/terms-and-conditions-of-access.pdf

This article maybe used for research, teaching and private study purposes. Any substantial or systematic reproduction, re-distribution, re-selling, loan or sub-licensing, systematic supply or distribution in any form to anyone is expressly forbidden.

The publisher does not give any warranty express or implied or make any representation that the contents will be complete or accurate or up to date. The accuracy of any instructions, formulae and drug doses should be independently verified with primary sources. The publisher shall not be liable for any loss, actions, claims, proceedings, demand or costs or damages whatsoever or howsoever caused arising directly or indirectly in connection with or arising out of the use of this material.

(C) Taylor and Francis 2007 
Intern. J. Environ. Anal. Chem.

Vol. 87, Nos. 10-11, 20 August-15 September 2007, 701-714

Taylor \& Francis

Taylor \& Francis Group

\title{
Biosensors based on gold nanoelectrode ensembles and screen printed electrodes
}

\author{
WALTER VASTARELLA $\uparrow$, LIVIA DELLA SETA $\uparrow$, AMEDEO MASCI $\dagger$, \\ JAN MALY $\$$, MANUELA DE LEO§, LIGIA MARIA MORETTO§ \\ and ROBERTO PILLOTON*† \\ $\dagger$ ENEA-CR Casaccia, Via Anguillarese 301-SP061 I-00060 S. Maria di Galeria Rome, Italy \\ tDepartment of Biology, University of J.E. Purkyne, 40001 Usti nad Labem, \\ Czech Republic \\ §Dipartimento di Chimica Fisica, Università Ca’ Foscari di Venezia, Santa Marta 2137, \\ I-30123 Venice, Italy
}

(Received 20 October 2006; in final form 24 January 2007)

\begin{abstract}
Gold nanowires were synthesized within polycarbonate membranes according to an electroless deposition method, obtaining nanoelectrode ensembles (NEEs) with special electrochemical features. NEEs were coupled with home-produced carbon graphite screen printed electrodes and the electrochemical properties of the original nanoelectrode ensemble on screen printed substrate (NEE/SPS) assembly has been tested for sensors application. Glucose oxidase has been used as model enzyme in order to verify the feasibility of disposable gold NEE/SPS biosensors. Finally, different immobilisation and electrochemical deposition techniques based on either self assembled monolayers of cysteamine (CYS) or amino-propyl-triethoxysilane (APTES) and conductive polyaniline (PANI) molecular wires were used. Spatial patterning of the enzyme on the polycarbonate surface and of PANI wires on gold nanoelectrodes was obtained. Possible direct electron transfer between the enzyme and the PANI modified gold nanoelectrodes has been evaluated.
\end{abstract}

Keywords: Gold nanoelectrode ensemble; Glucose biosensor; Self assembled monolayers; Screen printed substrate

\section{Introduction}

Nanostructured materials have proven as one of the most powerful tool in new technologies and research, due to their absolutely peculiar properties at nanometer size scale. Many studies have shown that optical, mechanical, photo-catalytic and transport properties drastically changes, depending on quantum size effect, as the mean diameter

*Corresponding author. Fax: +390-630486591. Email: pilloton@casaccia.enea.it 
of the particles is in the exciton size regime (i.e. $10 \mathrm{~nm}$ ) [1-9]. As a matter of fact, metallic and semiconductor nanosized materials have found large applications in biochemistry [10-13], bioanalytical techniques as well as in photocatalysis [14, 15], optoelectronics [16], photo-electrochemistry [17]. The unique chemical and physical properties of nanoparticles make them suitable for designing new and improved sensing devices, especially electrochemical sensors and biosensors [18, 19]. The main functions of nanostructured particles for biosensing purposes include: immobilization of biomolecules [20-22], catalysis of electrochemical reactions [23, 24], enhancement of electron transfer mechanism between electrode surfaces and proteins [25-27], labelling of biomolecules and even acting as reactant [28-30]. On the other hand, the efficient assembly of biochemical recognizing systems on such sensors requires essentially:

- the control of the surface activation (i.e. using self-assembled monolayers SAM);

- the possible modification of the substrate;

- the immobilization process of biomolecules.

Due to its special characteristic of easily forming SAM through thio-derivative compounds, gold electrode has been often used as a transducer in electrochemical biosensors. For our purposes, nanowires of gold were synthesized into polycarbonate membranes with controlled pore size using an electroless deposition method, obtaining nanoelectrode ensembles (NEEs) with special electrochemical features [31-33].

Such electrode ensembles can be either used as platform for immobilization of biomolecules or as free standing NEEs, i.e. a large assembly of very small ultramicrolectrodes confined in a rather small space. In each case, NEEs can exhibit three distinct voltammetric response regimes, depending on the scan rate and reciprocal distance between the nanoelectrode elements, which is a function of the pore density of the template: total overlap regime, pure radial regime and linear regime. It was demonstrated that for electroanalytical applications the total overlap regime is the most advantageous one because of the higher faradaic-to-capacitive current ratios [31-33]. Under such regime, Au NEEs fabricated from commercial track-etched membranes present a signal to noise ratio in the order of $10^{2}$ respect to a conventional $\mathrm{Au}$ macro electrode with the same geometrical area [33].

NEEs were deposited on the working probe and coupled with carbon screen printed electrode (SPE) to give a novel easy to be used tool for disposable biosensors, which has been defined as nanoelectrode ensemble on screen printed substrate (NEE/SPS). Features of NEE/SPS based biosensors were electrochemically compared to unmodified carbon or conventional gold SPEs using immobilized glucose oxidase as biochemical model system. Sequential deposition of SAM or polyelectrolyte onto NEE/SPS has been experimented to extend the potential range of applicability for third generation biosensors where direct electron transfer between red-ox proteins and polymer modified gold nanoelectrodes has been achieved. The NEE/SPS preparation is aimed to couple the high electroanalytical sensitivities, deriving from the nanosized properties, with the feasibility and versatility of screen printing technology in easy to be used sensor fabrications. 


\section{Experimental}

\subsection{Chemicals and reagents}

Glucose oxidase (GOx) from Aspergillus niger (EC 1.1.3.4), with specific activity of 198 units per $\mathrm{mg}$ of solid, bovine serum albumin (BSA, stock solution: $4 \% \mathrm{w} / \mathrm{v}$ ), hydrogen peroxide, potassium ferricyanide, $\alpha$-methyl-ferrocenyl-methanol (MFME), glutaraldehyde (GA) 25\% aqueous solution, 3-amino-mercaptopropionic acid (CYS), formaldehyde, aniline, amino-propyl-triethoxysilane (APTES) solution, tin chloride, trifluoroacetic acid, silver nitrate, dehydrated gold chloride, sodium sulphite, potassium and sodium phosphate salts were purchased from Sigma-Aldrich. All reagents, buffer and electrolyte supporting solution, e.g. 0.1 M phosphate buffer (PB) solutions, were prepared from deionised water (Synergy 185 Millipore $^{\mathrm{TM}}$ apparatus). All other chemicals and solvents were of analytical grade and used without further purification.

\subsection{Apparatus}

All measurements were carried out with a FIA system, including a peristaltic pump Gilson $^{\mathrm{TM}}$ Model Minipuls 3, an injector valve (Omnifit ${ }^{\mathrm{TM}}$, Cambridge, England) with a $115 \mu \mathrm{L}$ volume sample injector loop, a Perspex homemade flow cell. The flowing solutions were conducted through the system by PTFE tubes of $0.8 \mathrm{~mm}$ i.d. at a fixed flow rate. Voltammetric and amperometric measurements performed respectively under batch and FIA conditions were conducted with the Autolab ${ }^{\mathrm{TM}}$ potentiostat PGSTAT10 provided with GPES electrochemical analysis system (ECOchemie). Amperometric measurements were also carried out by means of a lab-developed computer controlled potentiostat (Domotek ${ }^{\mathrm{TM}}$ ), applying the desired potential and allowing for steady state current to be reached.

Printed electrodes were obtained with a HT10 Fleischle ${ }^{\mathrm{TM}}$ screen printer (Brackenheim, Germany). Scanning electron microscope (SEM) JEOL JSM-5510 Low Vacuum model was used for the characterization of gold nanowires. The microscope is equipped with an Oxford Instrument EDS 2000 microanalysis detector and software for the elementary analysis. No sample coating was required for SEM observations.

\subsection{Synthesis of Au nanowires}

Amongst the plenty of methods to synthetize nanosized materials, the formation of metal, semiconductor, oxide and polymer nanowires or nanotubules via template synthesis represents one of the most simple and rapid one, especially when using nanoporous polycarbonate (PC) or alumina membranes as template system. Electroless deposition of Au was performed into track etched PC membrane (Unipore ${ }^{\mathrm{TM}}$, nominal pore size $30 \mathrm{~nm}$, thickness $10 \mu \mathrm{m}$, pore density $6 \times 10^{8}$ pores $\mathrm{cm}^{-2}$ ) according to the pioneering work of Martin and coworkers [31]. Track-etched polymer membranes are preferred for NEE fabrication over alumina membranes because of their smaller pore densities and their lower fragility. The original synthetic route was slightly modified, by immerging successively the membrane $40 \mathrm{~min}$ for the surface activation in $\mathrm{Sn}$ chloride 


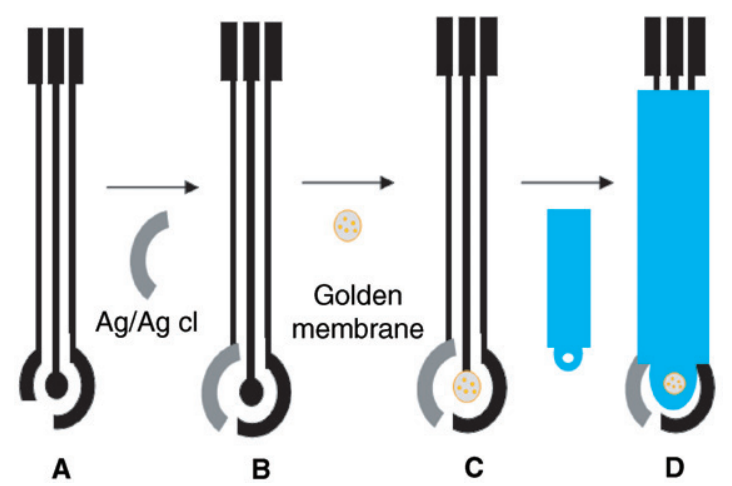

Figure 1. Schematic sequence of the printing process for NEE/SPS formation; (a) carbon graphite tracks and contact pads by screen printing; (b) $\mathrm{Ag} / \mathrm{AgCl}$ paste deposition for reference electrode; (c) deposition on the working of the NEE based membrane; (d) dielectric paste screen printing.

solution, $15 \mathrm{~min}$ in ammoniacal $\mathrm{AgNO}_{3}$ to allow $\mathrm{Ag}$ nanoparticles deposition, and $24 \mathrm{~h}$ at $4{ }^{\circ} \mathrm{C}$ in $\mathrm{AuCl}_{4}^{-}$solution for $\mathrm{Au}$ deposition by galvanic displacement [32]. Activation and Ag deposition were followed by accurate washing procedure with methanol, $\mathrm{Au}$ deposition was followed by washing with distilled water and further treatment in $\mathrm{HNO}_{3} 30 \%$ for $12 \mathrm{~h}$, in order to remove surface residues of $\mathrm{Sn}^{2+}$ and $\mathrm{Ag}$. Finally, the $\mathrm{Au}$ membrane was placed $15 \mathrm{~min}$ in oven at $150^{\circ} \mathrm{C}$ to enable a tight sealing of the gold wires.

\subsection{Nanoelectrode ensembles and screen printed substrate preparation}

Conducting and insulators inks were printed on $0.3-0.5 \mathrm{~mm}$ thick polyvinyl-chloride (PVC) substrate. Silver and carbon-graphite pastes for the conducting paths and working electrode (WE), as well as $\mathrm{Ag} / \mathrm{AgCl}$ for reference electrode (RE) and dielectric pastes were all from GWENT Electronics Materials Inc ${ }^{\mathrm{TM}}$.

In order to assemble $\mathrm{Au}$ nanoelectrodes based membrane with screen printed substrates, NEE membrane was one side peeled and soaked only on the rear side into a wet graphite ink pad. Either a vacuum pen or a vacuum-controlled silicone rubber tube were conveniently used for placing the inked membrane on the graphite WE. Afterwards, the device was completed by printing insulator and RE layers as in common screen printing procedure. Figure 1 shows the novel sequence of the screen printing for disposable NEE/SPS production. In each case, the active WE area of $2.54 \mathrm{~mm}^{2}$ is defined by the insulator geometry.

\subsection{NEE/SPS characterization and biosensing}

As depicted in figure 2, a home made flow cell was used for the characterization of NEE/SPS and successively, for the amperometric detection of glucose with a glucose oxidase (GOx) based biosensor. The microcell was tailored with appropriate dimensions and inner electrical connections, in order to tightly lodge the screen printed substrate on the bottom surface of the Perspex block. The NEE/SPS was screwed between these two polymer blocks, leaving two holes in the upper side equipped for connection to 
(a)

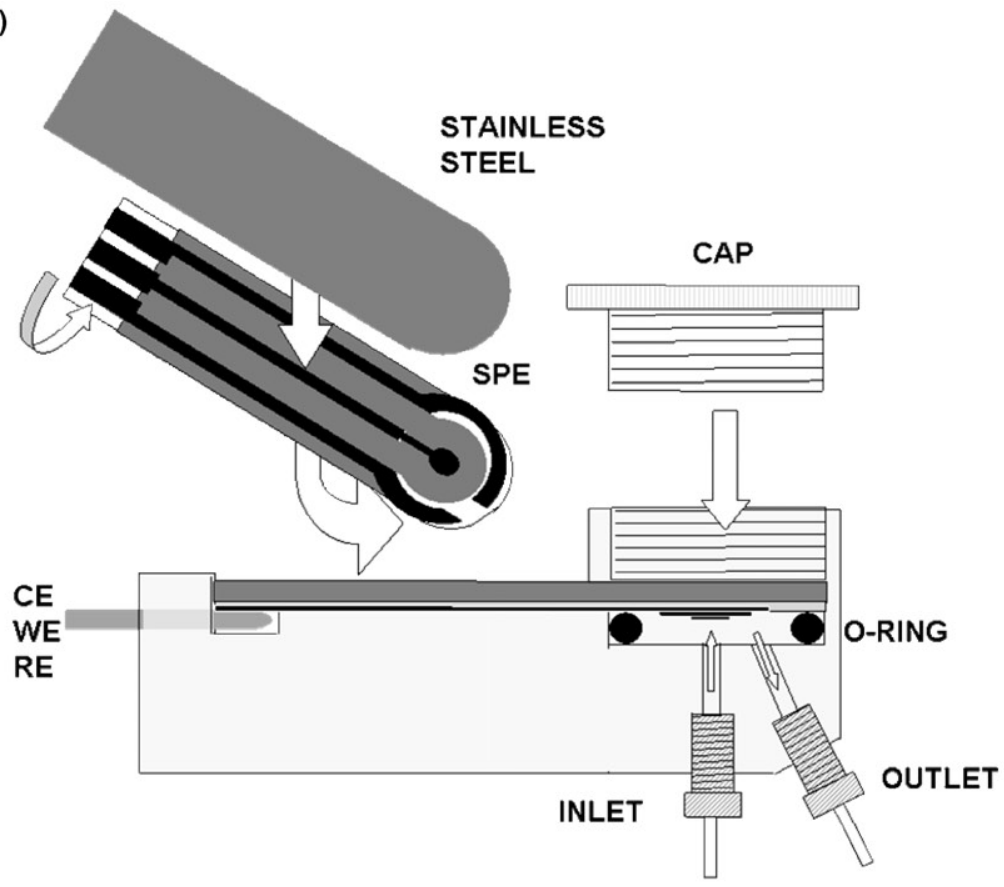

(b)

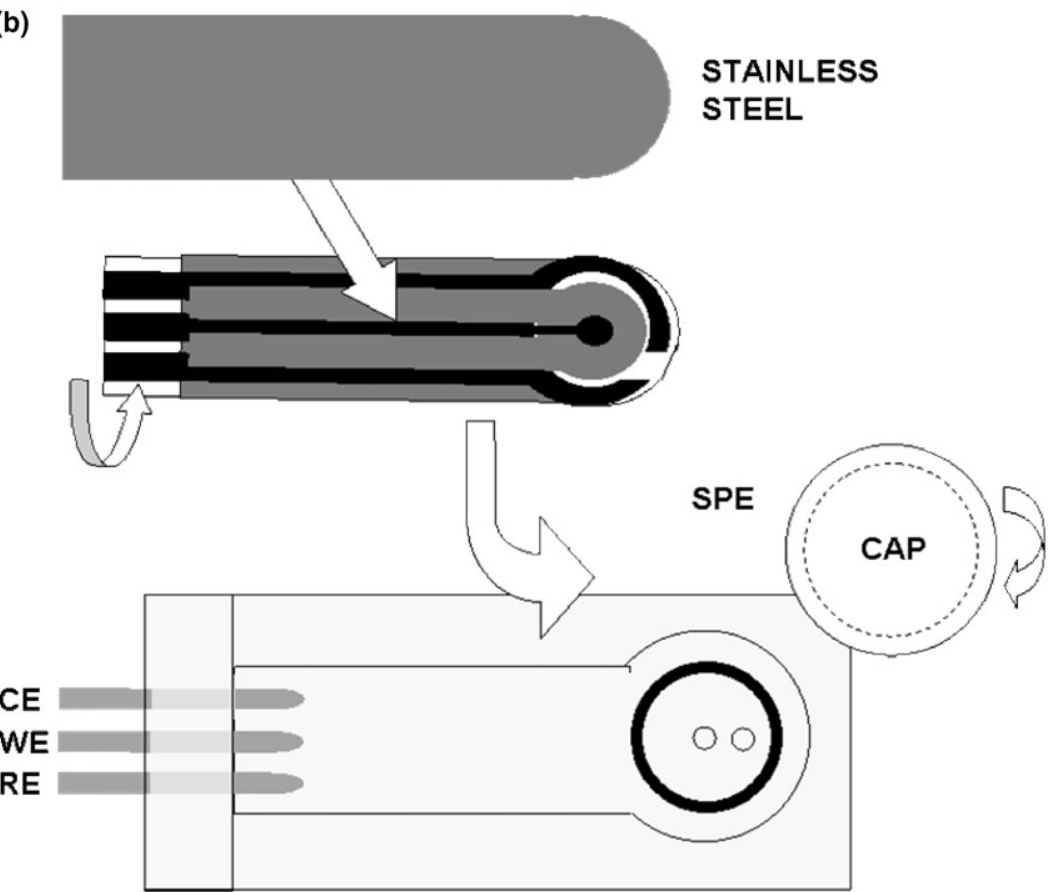

Figure 2. Schematic diagram of the home-made flow cell. Insertion of the screen printed electrode is favoured by a stainless steel lamina which presses the printed pads on gold coated pins for electric contacts with a nylon screwed cap. (a) side view, (b) top view. 
the sample loop $(115 \mu \mathrm{L})$ via Teflon tubing. The peristaltic pump was used to propel solution along a flow injection analysis (FIA) system. PB was used as a carrier in all the following experiments.

\subsection{Enzyme immobilization on NEE/SPS}

The aim of this preliminary work was to evaluate the response to a substrate sample after immobilization of the corresponding enzyme on NEE/SPS. GOx immobilization was used as a model system to test feasibility of the sensing probe and analytical performances of nanoelectrodes assembled at a SPE. The preparation of NEEs, was followed by the SAM formation and subsequent covalent attachment of the enzyme. Well experimented methodologies was chosen for immobilization of GOx on $\mathrm{Au}$ element:

(a) CYS was assembled on Au nanodisks either electrochemically $(20 \mathrm{~s}$ of $21 \mathrm{mM}$ CYS growth at $+800 \mathrm{mV} v s$. RE) or chemically (immerging for $16 \mathrm{~h}$ the NEE/SPS in a solution of $21 \mathrm{mM} \mathrm{CYS).} \mathrm{The} \mathrm{electrochemical} \mathrm{deposition} \mathrm{of} \mathrm{CYS}$ has been demonstrated to be effective on pure gold electrode as well as on screen printed Au-graphite [35]. This treatment left on the top surface free available amine groups. For this reason GA was chosen as a coupling agent; SAM/NEE/ SPS was immersed for $1 \mathrm{~h}$ in a $12.5 \% \mathrm{v} / \mathrm{v}$ solution of GA and afterwards washed with buffer. Freshly prepared GOx buffered solution $\left(6 \mathrm{mg} \mathrm{mL}^{-1}\right)$ was dropped on GA/SAM/NEE/SPS and left to be covalently attached thanks to the primary amine groups of the enzyme. The non-covalently bound enzyme as well as the excess of GA was removed by a three-fold washing process with buffer solution at $\mathrm{pH}$ 6.8. The sensor (GOx/SAM/NEE/SPS) was finally washed, dried in air and stored overnight in refrigerator at $4{ }^{\circ} \mathrm{C}$ before to be assayed.

(b) Alternatively, another immobilization method has also been set up, in order to achieve spatial patterning of the enzyme on PC membrane and conductive polymers on gold nanoelectrodes. By this way a direct electron transfer from the red-ox site of the enzyme to the electrode along the conductive polymer multilayer is obtained. Deposition of polyelectrolyte was assessed on the golden part of NEE/SPS, then covalent attachment of the enzyme was attempted on the rest of the membrane, according to the following sequence:

Polyaniline (PANI) was electrochemically deposed by cycling the electrode potential from -0.4 to $+1.0 \mathrm{~V}$ of $50 \mathrm{mM}$ aniline in diluted sulphuric acid $(0.5 \mathrm{M})$, as extensively reported in literature $[35,36]$. The working electrode obtained, constituted by polyaniline wires grown in the gold discs is now named PANI/NEE/SPS.

The PANI/NEE/SPS was immersed in a solution of $10 \% \mathrm{v} / \mathrm{v}$ APTES for $90 \mathrm{~min}$, in order to obtain a terminal amino group $\left(-\mathrm{NH}_{2}\right)$ onto the PC surface [35, 37]. The resulting derivative was accurately washed with $\mathrm{PB}$ solution $(\mathrm{pH} 6.8)$ and water. The PANI/NEE/SPS were then immersed for $1 \mathrm{~h}$ in a concentrated solution of GA $(12.5 \% \mathrm{v} / \mathrm{v})$ allowing the amino groups on the PC membrane to react in a stoichiometric ratio of 1:1 with GA, thus avoiding deprecable covalent bridging. Afterwards the unbound GA was removed by a three-fold washing with PB solution. At this step free carbonyl groups from GA facing on the PC surface are ready for the following reaction with the terminal amino groups of the enzyme. Freshly prepared GOx buffered solution $\left(6 \mathrm{mg} \mathrm{mL}^{-1}\right)$ was then dropped on the surface of the PANI/NEE/SPS and left to be 


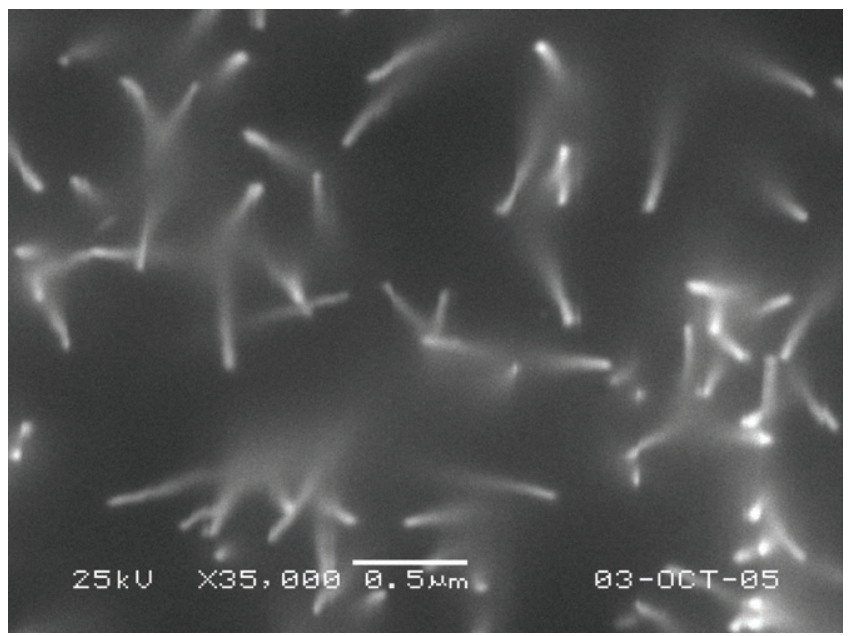

Figure 3. Scanning electron microscopy (SEM) image of Au nanowires deposited into nanoporous PC membranes with nominal pore size of $30 \mathrm{~nm}$.

covalently attached to the free carbonyl group; the unbound enzyme was then removed by a three-fold washing with PB solution. The resulting biosensor $(\mathrm{GOx} / \mathrm{PANI} / \mathrm{NEE} /$ SPS) was washed, dried in air and stored overnight at $4^{\circ} \mathrm{C}$.

\section{Results}

\subsection{Assays on bare NEE/SPS}

Scanning electron microscope (SEM) observations, as the one reported in figure 3, show the successful formation of $\mathrm{Au}$ nanowires with a mean diameter of $30 \mathrm{~nm}$ and a narrow size distribution. The image was obtained after peeling away the Au layer grown over the front side of the template membrane. From the figure, nanowires density can be also calculated of around 6 pores $\mu \mathrm{m}^{-2}$, in accordance with the declared pore density, thus confirming each template pore was filled with gold.

Before the enzyme immobilization, NEE/SPS were tested with a redox probe by cyclic voltammetry at different scan rates. MFME was used as the probe because of its very well known behaviour [34]. Figure 4 shows the CV recorded at a NEE/SPS in $10^{-5} \mathrm{~mol} \mathrm{~L}^{-1}$ MFME solution at a scan rate of $100 \mathrm{mV} \mathrm{s}^{-1}$. The voltammetric pattern presents a quasi-reversible system with an anodic peak at $150 \pm 10 \mathrm{mV}$ and a cathodic peak at $-20 \pm 1 \mathrm{mV}$.

Anodic and cathodic peak currents $\left(I_{\mathrm{p}}\right)$ of NEE/SPS were in all the cases 2-3 orders of magnitude higher than conventional electrodes: theoretical calculations, applying the electroanalytical Randles-Sevcik equation, result in the ratio ( $f=$ fractional area) between active and geometric area $f=A_{\text {act }} / A_{\text {geom }}$ from $10^{-3}$ to $10^{-2}$. These observations are perfectly in accordance with the characteristic of nanoelectrodes under total overlap diffusional regime [32-34, 39]. 


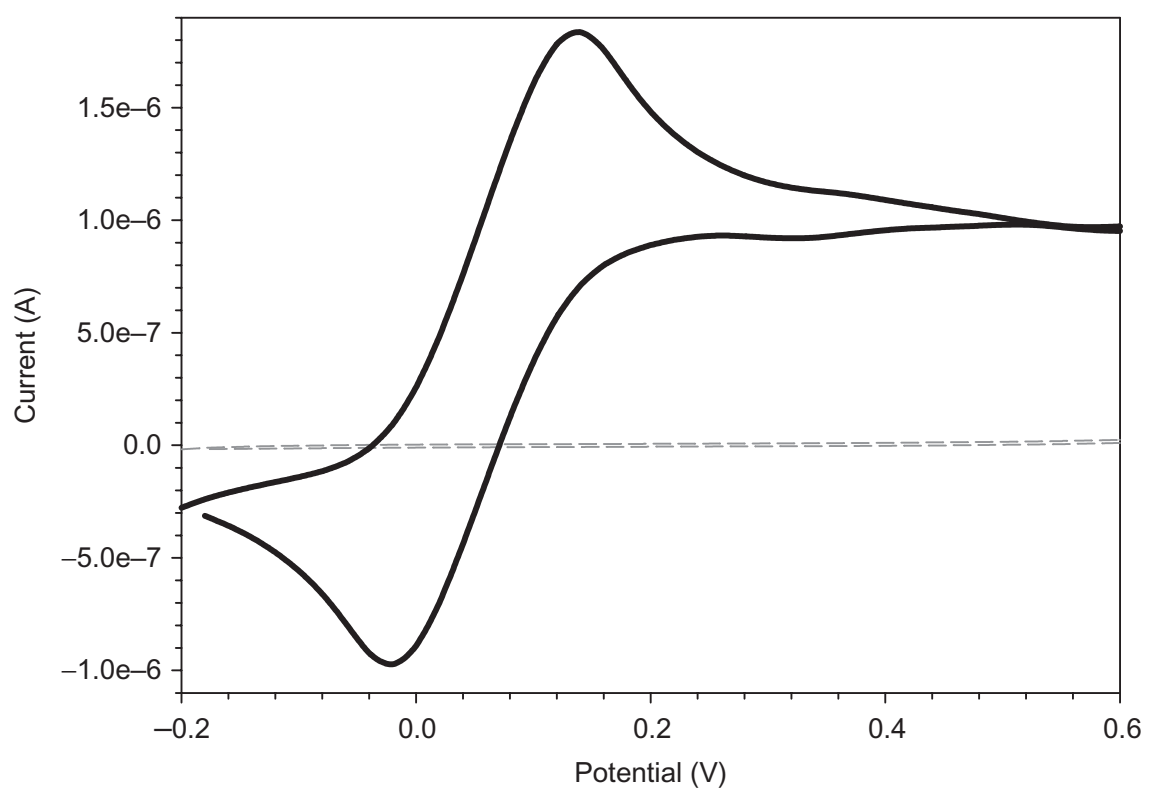

Figure 4. Cyclic voltammograms recorded using a typical NEE/SPS in $10^{-3} \mathrm{~mol} \mathrm{~L}^{-1} \mathrm{NaNO}_{3}$ as supporting electrolyte (dashed line) and after addition of $10^{-5} \mathrm{~mol} \mathrm{~L}^{-1} \alpha$-methyl ferrocenyl methanol (solid line); scan rate $100 \mathrm{mV} \mathrm{s}^{-1}$; step potential $10 \mathrm{mV}$; reference electrode: internal $\mathrm{Ag} / \mathrm{AgCl}$.

Figure 5 shows the voltammetric response recorded at $50 \mathrm{mV} \mathrm{s}^{-1}$ at different concentration values of the redox probe $\left(1,11\right.$ and $28 \times 10^{-5} \mathrm{~mol} \mathrm{~L}^{-1}$ of MFME) in the supporting electrolyte $\left(10^{-3} \mathrm{~mol} \mathrm{~L}^{-1} \quad \mathrm{NaNO}_{3}\right)$. In the inset the corresponding calibration plot indicates that the NEE/SPS gives a linear response respect to the analyte concentration in this range (linear correlation coefficient $r^{2}=0.998$ ).

CYS deposition on Au NEE/SPS was accomplished as reported in the previous experimental section. The effectiveness of this proccess is confirmed by observing the trend of the oxidation peak (centered at around $+800 \mathrm{mV}$ ) that decreases after few scans of CV. As already reported in the case of Au and graphite traditional SPE [35], this behaviour is due to the rapid deposition of CYS till the saturation of the electrode surface [35]. Chronoamperometric measurements gave a maximum oxidation current response which is two orders of magnitude lower than in the case of CYS deposed on Au screen printed probes. Since CYS is immobilised just on the Au surface, to compare the results obtained at NEE, NEE/SPS and gold electrodes, current densities should be calculated. Therefore, it is necessary to evaluate the NEE active surface. Taking into account the declared pore density of the template membrane (which corresponds approximately to the Au nanodisks density in the NEE) and the area of a single nanodisk (declared pore diameter of $30 \mathrm{~nm}$ or measured [45] as about $50 \mathrm{~nm}$ in a previous paper by SEM), active areas can be calculated for conventional NEE and for NEE/SPS. Table 1 summarizes the result of the comparison among three different gold probes:

- gold electrodes obtained by galvanic deposition of $\mathrm{Au}$ on copper paths with a rugosity factor of 1.13 as previously described [35],

- gold NEE produced according to [31] and modified in [38],

- gold NEE/SPS prepared with our method. 


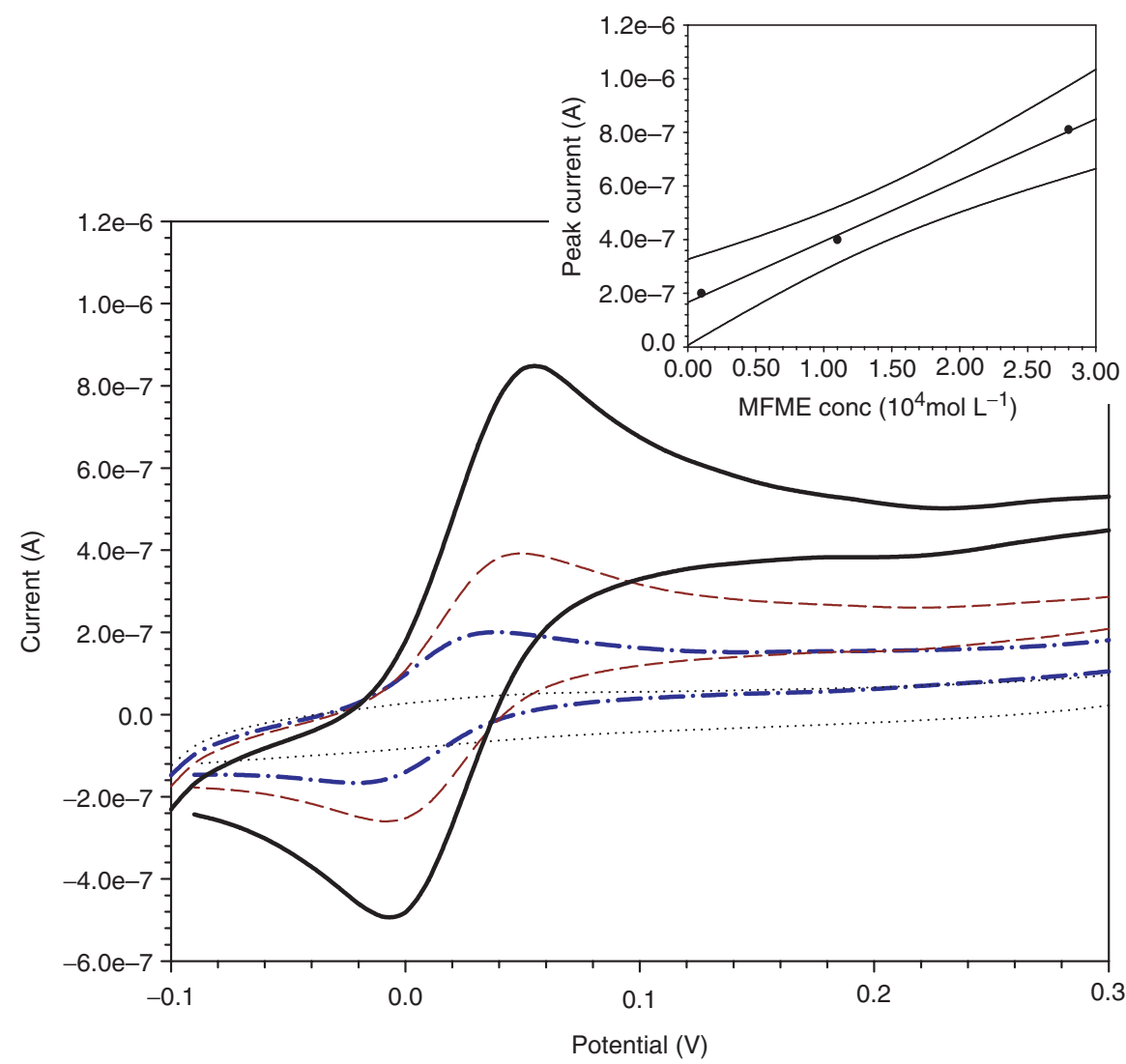

Figure 5. Cyclic voltammograms recorded at typical NEE/SPS at different $\alpha$-methyl ferrocenyl methanol (MFME) concentration in supporting electrolyte $\left(10^{-3} \mathrm{~mol} \mathrm{~L}^{-1} \mathrm{NaNO}_{3}\right)$; scan rate $50 \mathrm{mV} \mathrm{s}^{-1}$; step potential $10 \mathrm{mV}$; reference electrode: internal $\mathrm{Ag} / \mathrm{AgCl}$.

Dotted line supporting electrolyte $\left(10^{-3} \mathrm{~mol} \mathrm{~L}^{-1} \mathrm{NaNO}_{3}\right)$, dash-dotted line $10^{-5} \mathrm{~mol} \mathrm{~L}-1$ MFME, dashed line $1.1 \times 10^{-4} \mathrm{~mol} \mathrm{~L}^{-1} \mathrm{MFME}$, solid line $2.8 \times 10^{-4} \mathrm{~mol} \mathrm{~L}^{-1} \mathrm{MFME}$. The inset shows the calibration curve (3 points with 4 replicates per point): $r^{2}=0.9977$, with the following equation: $I_{\mathrm{p}}(A)=(1.66 \pm 0.09) \times 10^{-7}+(2.27 \pm 0.06) \times 10^{-7} \mathrm{C}(\mathrm{M})$.

Table 1. A comparison of peak current due to electrochemical oxidation of $21 \mathrm{mM}$ CYS amongst several NEE assemblies using a gold electrode [35], a conventional NEE and NEE/SPS at $+800 \mathrm{mV} v s$. Pt in a two-electrode configuration.

\begin{tabular}{lccccc}
\hline & $\begin{array}{c}\text { (a) Peak } \\
\text { current } \\
I_{\mathrm{p}}(\mu \mathrm{A})\end{array}$ & $\begin{array}{c}\text { (b) Geometric } \\
\text { area } \\
\left(\mathrm{cm}^{2}\right)\end{array}$ & $\begin{array}{c}(\mathrm{d}) \text { Conversion } \\
\text { factor* }\end{array}$ & $\begin{array}{c}\text { Active area } \\
\left(\mathrm{cm}^{2}\right)\end{array}$ & $\begin{array}{c}(\mathrm{e}=a / d) \text { Current } \\
\text { density } \\
\left(\mathrm{mA} \mathrm{cm}^{-2}\right)\end{array}$ \\
\hline $\begin{array}{l}\mathrm{Au} \\
\mathrm{Au} \mathrm{NEE}\end{array}$ & 625.0 & 0.143 & $*^{1} 1.1330$ & $1620.00 \times 10^{-4}$ & 3.86 \\
$\begin{array}{l}\text { Pore diameter }=30 \mathrm{~nm} \\
\text { Pore diameter }=50 \mathrm{~nm}\end{array}$ & 0.5 & 0.071 & $*^{2} 0.0042$ & $3.07 \times 10^{-4}$ & 1.66 \\
$\begin{array}{l}\text { Au NEE } / \mathrm{SPS} \\
\text { Pore diameter }=30 \mathrm{~nm}\end{array}$ & 1.5 & 0.071 & $*^{2} 0.0118$ & $5.95 \times 10^{-4}$ & 0.60 \\
Pore diameter $=50 \mathrm{~nm}$ & 1.5 & 0.025 & $*^{2} 0.0042$ & $1.08 \times 10^{-4}$ & 14.15 \\
\end{tabular}

*1 dimensionless, $f_{\mathrm{r}}=$ rugosity factor $=A_{\mathrm{r}} / A_{\mathrm{g}}$, the ratio between the real and the geometric surface areas of the gold electrode used [35].

$*^{2}$ dimensionless, $f=$ fractional area $=A_{\mathrm{a}} / A_{\mathrm{g}}$, the ratio between active and geometric areas of NEEs, calculated considering the pore diameter equal to $30 \mathrm{~nm}$ as declared by the producer or equal to $50 \mathrm{~nm}$ as a mean value of SEM measurements previously reported by some of the authors in [45]. 


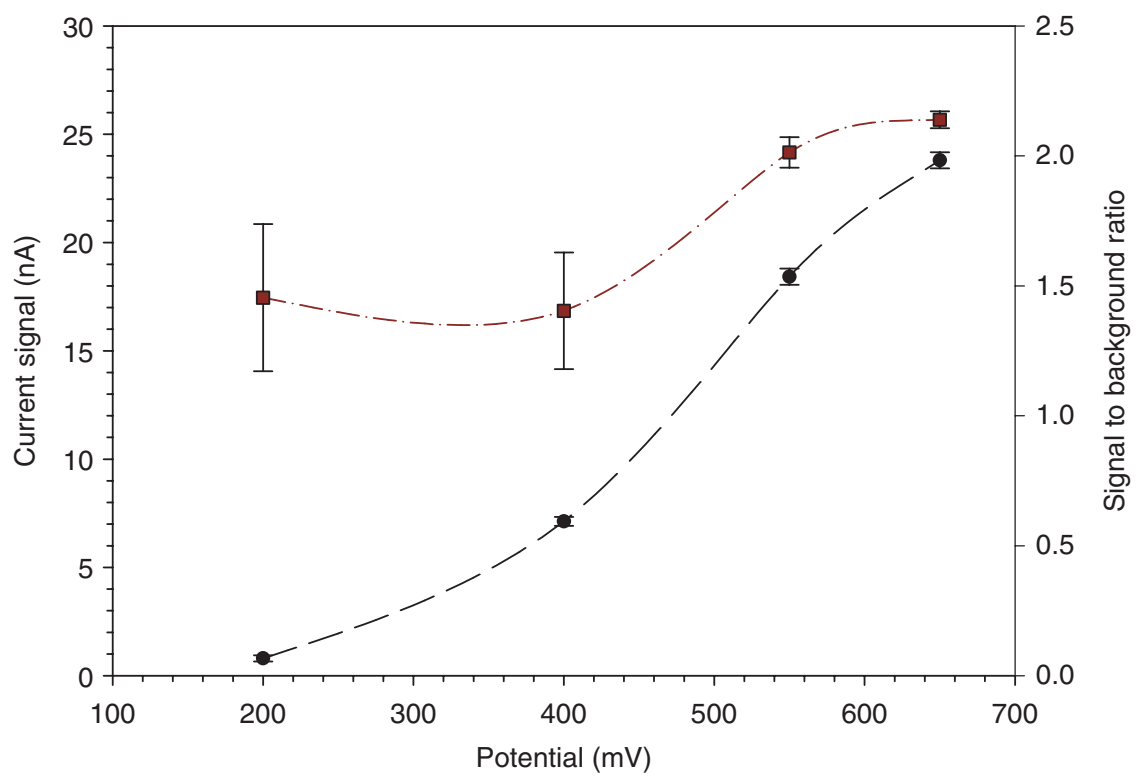

Figure 6. Signal to background ratio (circles, right $Y$ axis) and current (squares, left $Y$ axis) vs. the applied potential; injections of $10^{-3} \mathrm{M}$ glucose in PB solution at $\mathrm{pH} 6.8$ on GOx/SAM/NEE/SPS biosensor; sample loop: $115 \mu \mathrm{L}$, flow rate: $0.4 \mathrm{~mL} \mathrm{~min}^{-1}$.

In the last column of table 1 the higher current density for CYS $21 \mathrm{mM}$ is obtained with NEE/SPS assembly. This result is probably due to a more effective contact between the gold nano wires facing the screen printed conducting path. Additionally, current density obtained with NEE/SPS resulted higher than gold electrode probably due to the NEE structure.

\subsection{Analytical performance of NEE/SPS based sensor for glucose}

The glucose sensor was implemented in the home made flow-through detection cell (figure 2), therefore flow injection conditions were optimized for the highest current signal: the optimal flow rate was reached at $0.4 \mathrm{~mL} \mathrm{~min}^{-1}$, using a sample loop of $115 \mu \mathrm{L}$. Figure 6 shows the signal to background ratio (circles) as well as the response of current (squares) at different applied potential, due to the oxidation of the produced $\mathrm{H}_{2} \mathrm{O}_{2}$, when multiple injections of $10^{-3} \mathrm{M}$ glucose sample were performed on the same $\mathrm{GOx} / \mathrm{SAM} / \mathrm{NEE} / \mathrm{SPS}$. Background curve is not reported because of scaling reasons. The background current drastically increased with decreasing potential owing to desorption/reduction of CYS (data not shown) which is treated in a specific paper by some of the authors (in press).

The unmodified NEE/SPS did not respond to glucose, confirming that aspecific oxidation at the Au surface does not take place. The best signal to noise ratio was achieved in this sensor within the range $+550 / 650 \mathrm{mV}$.

The response of the biosensor to glucose concentration presents a linear behaviour $\left(R^{2}=0.993\right)$ between $1.0 \times 10^{-4}$ and $3.1 \times 10^{-2} \mathrm{M}$, which is within the analytical range for blood monitoring [40]. At higher glucose concentration, where saturation of 
Table 2. A comparison of the analytical performances of different gold nanoelectrode ensemble based biosensor for detection of glucose (data from literature [41] in the 1st column, our experimental data in the other columns). GOx/SAM/NEE/SPS: GOx covalently immobilized via CYS self assembled monolayers and glutaraldehyde on gold NEE disposable sensor; PANI/GOx/NEE/SPS: GOx covalently immobilized on the membrane via amino propyl trietoxysilane-GA, polyaniline grown on gold NEE; GOx/GA/MPE/Au NEE [41]: GOx covalently immobilized on gold nanaoelectrodes via a mercapto-compound, GOx/SAM/Au SPE: GOx covalently immobilized via CYS self assembled monolayers on a commercially available gold SPE (BVT Technologies, CZ).

\begin{tabular}{|c|c|c|c|c|}
\hline $\begin{array}{l}\text { Sensors } \\
\text { configuration }\end{array}$ & $\begin{array}{c}\mathrm{GOx} / \mathrm{GA} / \mathrm{MPE} / \mathrm{Au} \\
\mathrm{NEE}(41)\end{array}$ & GOx/SAM/NEE/SPS & $\begin{array}{c}\mathrm{GOx} / \mathrm{SAM} / \mathrm{Au} \\
\mathrm{SPE}\end{array}$ & $\mathrm{PANI} / \mathrm{GOx} / \mathrm{NEE} / \mathrm{SPS}$ \\
\hline Explored range (mM) & - & $7.5 \times 10^{-3} \div 30$ & $0.2 \div 20$ & $1.9 \times 10^{-2} \div 20$ \\
\hline Linearity range (mM) & Up to 30 & $1.0 \times 10^{-1} \div 30$ & $1 \div 20$ & $1.0 \times 10^{-1} \div 20$ \\
\hline Sensitivity $\left(\mathrm{nA} \mathrm{mM} \mathrm{m}^{-1}\right)$ & 110 & 35 & 0.9 & 18 \\
\hline Reproducibility $(\%)^{1}$ & $3.7(n=38)$ & $3.9(n=35)$ & $14.2(n=28)$ & $4.4(n=35)$ \\
\hline 1.o.d. (mM) & 0.20 & 0.15 & 1.00 & 0.15 \\
\hline$K_{\mathrm{m}(\mathrm{app})}(\mathrm{mM})$ & 13.7 & 14.9 & - & 8.9 \\
\hline Shelf stability (days) & Not reported & 20 & 2 & 15 \\
\hline
\end{tabular}

${ }^{1} 0.5 \mathrm{mM}$ glucose injected $n$ times.

enzymatic active sites takes place, the response is no more linear. Sensitivity for $\mathrm{GOx} / \mathrm{SAM} / \mathrm{NEE} / \mathrm{SPS}$ was calculated from the slope of the calibration curve and was $34.6 \mathrm{nA} \mathrm{mM}^{-1}$ glucose. Limit of detection (1.o.d.) of $1.5 \times 10^{-4} \mathrm{M}$ was calculated with the Zund-Meier method [39]. The linear range can be estimated using Michaelis-Menten analysis of the calibration plot: an apparent constant of $14.9 \mathrm{mM}$ was obtained with non-linear curve fitting and the value was significantly lower than that of the native enzyme $(33 \mathrm{mM})[40]$.

High operational stability was also achieved within $48 \mathrm{~h}$ of continuous glucose injection. Shelf stability was measured repeating the calibration curve of glucose at a defined frequency (each two days); the sensor was dry stored in refrigerator during the rest period. The shelf lifetime of the sensor was expressed in table 2 as the period corresponding to the $90 \%$ of the initial response and the value for GOx/SAM/NEE/ SPS was 20 days.

\subsection{Performance of PANI/NEE/SPS sensor for glucose}

The biosensor made of PANI wires on NEE/SPS with GOx covalently immobilized was tested under the flow conditions above described. The dependence of the signal and signal to noise ratio on the buffer $\mathrm{pH}$ gave similar results (data not shown) in accordance with the GOx/SAM/NEE/SPS sensor.

The response of the PANI/GOx/NEE/SPS biosensor is linear $\left(R^{2}=0.998\right)$ in the concentration range of glucose from $10^{-4}$ to $2.0 \times 10^{-2} \mathrm{M}$ (table 2).

Amperometric FIA traces for both sensors were also compared in figure 7 at the concentration level of $0.5 \mathrm{mM}$ glucose. Normalised plots have been reported for both sensors considering equal to 1 the height of the current peak for both signals. The faster response times in the case of PANI/GOx/NEE/SPS biosensor could be due to the direct electron transfer to the electrode along the PANI wires. The sensitivity was $18.2 \mathrm{nA} \mathrm{mM}^{-1}$ glucose and 1.o.d. was $1.5 \times 10^{-4} \mathrm{M}$. A Michaelis-Menten apparent constant of $8.9 \mathrm{mM}$ was obtained. Shelf lifetime at $90 \%$ of response was 15 days. 


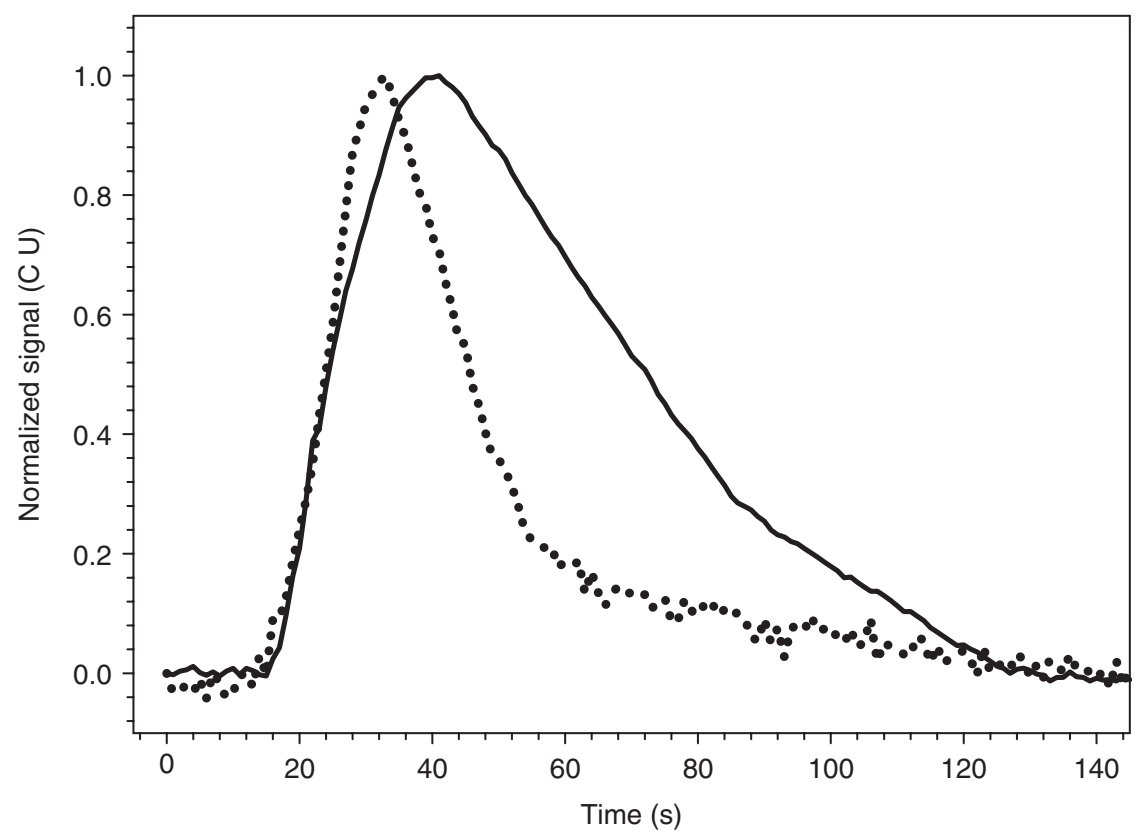

Figure 7. FIA responses for the proposed biosensors. Solid line, GOx/SAM/NEE/SPS: GOx covalently immobilized via CYS self assembled monolayers and glutaraldehyde only on the surface of gold NEE. Dotted line, PANI/GOx/NEE/SPS: GOx covalently immobilized on the PC membrane via amino propyl trietoxysilane and GA, polyaniline grown on gold NEE.

The achieved long term stability for PANI/GOx/NEE/SPS biosensor excludes the fact that simple physical adsorption of enzyme on the surface took place. This fact confirms the role of sililating agent to react with polycarbonate and consequently, to allow covalent bond between enzyme and NEE/SPS surface.

Analytical performances of GOx/SAM/NEE/SPS and PANI/GOx/NEE/SPS sensors were both compared with those available from literature in similar glucose biosensing devices based on Au NEE [41]. Analogue comparison has been made adopting the former immobilization procedure of GOx on a commercially available ceramic SPE (BVT Technologies, CZ) provided with pure gold working electrode (GOx/SAM/Au SPE). All these results are summarized in table 2. With respect to the literature data, detection limits for glucose are still not comparable with the characteristic of high sensitivity inherent with nanoelectrode ensemble [42]. This partial loss of the good performance of the NEEs may be ascribed to the number of layers grown on the surface during the immobilization procedure which were not still optimised at this time.

Furthermore, bare NEEs are usually selected by their performances operating in CV [31-34], while GOx based NEE are used under different operative conditions, with amperometric flow measurements. The effects of such conditions on nanostructures properties, as for instance the combination of diffusion pathways at the NEE and flow lines under the constrained geometry of a thin layer flow cell, are under investigation.

In each case, especially when using PANI wires along with covalent immobilization of GOx, our sensors are most valuable in a number of features, such as the linear dynamic range, the reproducibility (respectively $4.4 \%$ of relative standard deviations) and the limit of detection. 


\section{Conclusions}

Using an electroless procedure for the deposition of $\mathrm{Au}$ nanowires into nanoporous template membranes, nanoelectrode ensembles (NEEs) with interesting mechanical, and electrochemical properties, as well as unique surface chemistry were prepared. The assembly of screen printed substrates (SPS) in association with these nanosized component resulted in an original system of NEE/SPS for biosensor applications. NEE/SPS were preliminarily tested in a glucose oxidase based sensor under FIA conditions. High reproducibility, stability, and linearity of the electrochemical response of the overall system were successfully achieved. Sensitivity has not been increased with respect to commercially available glucose sensor. According to this novel approach, the well-known advantages of nanostructured material properties (such as higher signal to background ratio than conventional electrode) have been enhanced with the typical features of thick film technology in screen printing production (such as disposability, flexibility, durability of the product). Patterned immobilisation of GOx on PC membrane and of PANI on gold nanowires has been preliminarily proved and verified.

\section{Acknowledgements}

These experiments have been supported by FIRB, the Italian Fund for Fundamental Research and by CoSMiC, the ENEA target Project on Biosensors and Bioelectronics - www.biosensing.net.

\section{References}

[1] M. Nirmal, D.J. Norris, M. Kuno, M.G. Bawendi, A.L. Efros, M. Rosen. Phys. Rev. Lett., 75, 3728 (1995)

[2] L. Manna, E.C. Scher, A.P. Alivisatos. J. Cluster Sci., 13, 521 (2002).

[3] A.P. Alivisatos. Science, 271, 933 (1996).

[4] C.M. Lieber. Solid State Comm., 107, 607 (1998).

[5] V. Albe, C. Jouanin, D. Bertho. J. Crys. Growth, 185, 388 (1998).

[6] R.E. Smalley, B.I. Yakobson. Solid State Comm., 107, 597 (1998).

[7] A.J. Williamson, A. Zunger. Phys. Rev. B-Condens. Matter, 59, 15819 (1999).

[8] M. Bruchez, M. Moronne, P. Gin, S. Weiss, A.P. Alivisatos. Science, 281, 2013 (1998).

[9] A.P. Alivisatos. J. Phys. Chem., 100, 13226 (1996).

[10] P. Gouma, K. Kalyanasundaram, A. Bishop. J. Mater. Res., 21, 2904 (2006).

[11] M. Reches, E. Gasit. Curr. Nanosci., 2, 105 (2006).

[12] B. Zhang, C. Liu, H.M. Cheng, Q.K.C. Cai. New Carbon Mater., 18, 174 (2003).

[13] W.J. Guan, Y. Li, Y.Q. Chen, X.B. Zhang, G.Q. Hu. Biosen. Bioelectron., 21, 508 (2005).

[14] H.M. Zhang, X. Quan, S. Chen, H.M. Zhao. Environ. Sci. Technol., 40, 6104 (2006).

[15] D.V. Bavykin, J.M. Friedrich, F.C. Walsch. Adv. Mater., 18, 2807 (2006).

[16] P. Avouris, J. Chen. Mater. Today, 9, 46 (2006).

[17] S.K. Min, O.S. Joo, K.D. Jung, R.S. Mane, S.H. Han. Electrochem. Commun., 8, 223 (2006).

[18] W. Vastarella, R. Nicastri. Talanta, 66, 627 (2005).

[19] B. Dubertret, M. Calame, A.J. Libchaber. Nature Biotechnol., 19, 365 (2001).

[20] H. Ago, E. Uchimura, T. Saito, S. Ohshima, N. Ishigami, M. Tsuji, M. Yumura, M. Miyake. Mater. Lett., 60, 3851 (2006).

[21] X.H. Li, Z.H. Xie, H. Min, C.X. Li, M.C. Liu, Y.Z. Xian, L.T. Jin. Electroanalysss, 18, 2163 (2006).

[22] B. Corzilius, A. Gembus, N. Weiden, K.P. Dinse, K. Hata. Phys. Status Solvd B., 243, 3273 (2006). 
[23] C. Ponce-de-Leon, D.V. Bavykin, F.C. Walsch. Electrochem. Commun., 8, 1655 (2006).

[24] E. Lafuente, E. Munoz, A.M. Benito, W.K. Maser, M.T. Martinez, F. Alcaide, L. Gamborena, I. Cendoya, O. Miguel, J. Rodriguez, E.P. Urriolabeitia, R. Navarro. J. Mater. Res., 21, 2841 (2006).

[25] L. Chen, G.X. Lu. J. Electroanal. Chem., 597, 51 (2006).

[26] K. Teker, E. Wickstrom, B. Panchapakesan. IEEE Sensors J., 6, 1422 (2006).

[27] C.J. Zhong, W.X. Zheng, F.L. Leibowitz. Electrochem. Commun., 1, 72 (1999).

[28] N.G. Portney, M. Ozkan. Anal. Broanal. Chem., 384, 620 (2006).

[29] V.V. Didenko, D.S. Baskin. Brotechnqques, 40, 295 (2006).

[30] Q. Lu, J.M. Moore, G. Huang, A.S. Mount, A.M. Rao, L.L. Larcom, P.C. Ke. Nano Lett., 4, 2473 (2004).

[31] V.P. Menon, C.R. Martin. Anal. Chem., 67, 1920 (1995).

[32] B. Brunetti, P. Ugo, L.M. Moretto, C.R. Martin. J. Electroanal. Chem., 491, 166 (2000).

[33] L.M. Moretto, N. Pepe, P. Ugo. Talanta, 62, 1055 (2003).

[34] P. Ugo, L.M. Moretto. In Handbook of Electrochemistry, C. Zoski (Ed.), pp. 678-709, Elsevier Science (2006).

[35] J. Maly, C. DiMeo, M. DeFrancesco, A. Masci, J. Masojidek, M. Sugiura, A. Volpe, R. Pilloton. Bioelectrochemistry, 63, 271 (2004).

[36] T.A. Sergeeva, S.A. Piletskii, A.E. Rachkov, A.V. Elskaya. J. Anal. Chem., 51, 394 (1996).

[37] J. Maly, E. Illiano, M. Sabato, M. De Francesco, V. Pinto, A. Masci, D. Masci, J. Masojidek, M. Sugiura, R. Franconi, R. Pilloton. Mater. Sci. Eng., C22, 257 (2002).

[38] F.C. Pereira, L.M. Moretto, M. DeLeo, M.V. Boldrin Zanoni, P. Ugo. Anal. Chim. Acta, 575, 16 (2006).

[39] P.C. Meier, R.E. Zund. Statistical methods in analytical chemistry. In Chemical Analysis, J.D. Winefordner (Ed.), Vol. 123, p. 87, J. Wiley \& Sons Inc., New York (1993).

[40] B. Swoboda, V. Massey. J. Biol. Chem., 240, 2209 (1965).

[41] M. Delvaux, J. Duchet, S. Demoustier-Champagne, A. Walcarius. Electroanalysis, 16, 190 (2004).

[42] T.H. Hsia, K.T. Liao, H.J. Huang. Anal. Chim. Acta, 537, 315 (2005).

[43] E.S. Kilpatrick, M.J. Mcleod, A.G. Rumley, M. Small. Diabetic Med., 11, 214 (1994).

[44] P.A. Goldberg, J.E. Bozzo, P.G. Thomas, M.M. Mesmer, O.V. Shakarova, M.J. Radford, S.E. Inzucchi. Diabetes Technol. Therapeut., 8, 560 (2006).

[45] P. Ugo, N. Pepe, L.M. Moretto, M. Battagliarin. J. Electroanal. Chem., 560, 51 (2003). 